\title{
1. Introduction: a natural history of the car
}

\subsection{THE CAR}

If you are expecting a conventional academic book about the car industry, you are likely to be disappointed, so - to paraphrase a Dutch expression you may as well unhook here. Instead, this is to some extent an account of a personal journey, although it does occasionally stray into territory that may be recognizable to an academic - that is, after all, my background. The problem I have is that I am both a car enthusiast - a 'petrol head' if you like - and an environmentalist - a 'tree-hugger'. These two inclinations are, on the face of it, a challenge to reconcile. Yet, that is what I have been attempting to achieve over the past twenty-five years or so.

In the process I have become what one of my colleagues describes as 'a philosopher of the car industry'. This industry tends to be one of doers rather than thinkers; philosophers are therefore thin on the ground in the automotive industry, and this is increasingly a problem. As a society we are facing major issues, and the car has often been identified as a large part of the problem. Business as usual is not really going to address this, yet many are incapable of conceiving of a car industry other than the one we have today. Fortunately, some of us do have a few ideas of what such an alternative car system could look like, but it does require a major rethink, not only of the car and the industry that delivers it but, even more so, about our place in the world, more specifically the way we see ourselves in relation to what we call 'nature'.

Fortunately, my travels through 'carland' have also often featured encounters with truly original and creative thinkers within the industry, many embedded in the depths of research departments, engineering units or even, very occasionally, management. However, they remain few and far between. A similar lack of intellectual engagement can be found among those responsible for regulating this industry and, more surprising perhaps, among academics studying the industry, the latter often hampered by an expertise confined within a discipline rather than an industry sector. This leads them to look to the industry to provide evidence for a new bit of theory they have devised within the limits of their own discipline, rather 
than approaching it with an open mind, allowing a true understanding and using that to move to some form of higher-level analysis of the industry and its place in the world. Despite the fact that there are plenty of schools and academic departments of agriculture or mining, similarly specialist academic units that focus on the automotive sector beyond automotive engineering are very uncommon. Those in business schools who do look at the automotive sector - and there are surprisingly many - are often more like historians, looking at what was in the industry, very occasionally what is, but very rarely what could be.

Yet no sector - particularly at this time when its sustainability is increasingly being questioned - needs more understanding and intellectual input. Car and truck production is still one of the most important manufacturing sectors in economic, social, political and indeed environmental terms, never mind its cultural significance. If this important sector is to survive in some form, radical adjustments will be needed within a generation, yet at present large sections of the industry - focused as they are on the next model in what is usually these days a four- to eight-year product cycle - appear to bury their heads in the sand rather than face this uncertain future.

\subsection{TO MELT THE ICE IN THE HEART OF MAN}

The car is the most important artefact to emerge out of the 20th century. Though strictly speaking a 19th-century invention (see Chapter 4), its impact was not felt until the 20th century. That impact, when it came, was overwhelming. This book is about making car use and car making more sustainable. The argument is, first of all, that car use and car making are linked and that we cannot tackle one without tackling the other. This is the logic of the concept of sustainable consumption and production (SCP). However, I am taking things a step, or perhaps a giant leap, further by arguing that rather than being alien to nature, automobility and the car have a lot in common with natural phenomena, that they are in fact natural phenomena and it may even be possible to tackle the problems of automobility by understanding it as a natural phenomenon, a natural system.

At the core of any or all of these issues is ... us. We are at the heart of the matter, the problems and the solutions. We need to return to the realization that we are ourselves an integral part of nature: we are not only biomass; we are sentient, intelligent biomass. However, at present most of us do not recognize this simple fact. As Greenland shaman Angaangaq puts it: 'Only when we succeed in melting the ice in the heart of man, will a transformation be possible; a change that will enable us to meet the melting 
of the Big Ice - to cope with the outcome of climate change' (Angaangaq, 2011). Once this has happened we will realize that we share with the rest of the living world most of our genetic material, that we are in fact ourselves ecosystems, hosting a complex collection of other life forms (Arnold, 2013), and that with what we categorize as non-living fellow travellers on our planet we share our molecules - we are made up of 'matter': molecules, just like everything else. This includes a metal like iron - vital for both our life and that of our car. We nevertheless experience much of the rest of creation as 'strange'. Morton (2010) uses the term 'The Strange Stranger', which in reality includes most of our fellow humans as well as, in many respects, our own subconsciousness. In fact many people have a stronger emotional attachment to their mobile phone, or indeed their car, than to most fellow humans, suggesting perhaps that the nature of emotional ties is not confined to people, but can most definitely also include animals and minerals.

Over the centuries, we in 'the West' have come to think not only of humans as separate from the rest of creation, but also of human-made objects as quite distinct from natural objects. In reality this is a curious distinction; we do not think of ant hills, termite mounds, birds' nests, the 'bowers' of bower birds, or beaver dams in the same way, so what is so different about us? Many species change their environment to suit their own needs, or perceived needs. It has become clear, for example, that the ecological system of the Argentinian pampas is largely the result of the activities of various species of leafcutter ant (Tadey and Farji-Brener, 2007). Even the goldfish in my garden pond change their environment to suit their own needs. The pond existed for some time without them and a particular ecological equilibrium developed. After the goldfish were introduced, over the next couple of months or so, this ecosystem began to change; the water became clearer and greener as the goldfish's preferred crop began to coat the sides of the pond. After they had finished, a new but different equilibrium was reached that is now maintained by the activities of the goldfish and works in their interest, providing them with food, but from which some of the earlier species appear to have been excluded. The goldfish, therefore, change and manage their environment.

Also, be under no illusion that other species do not share our destructive nature; those who have seen the impact on a forest of a herd of elephants passing through, or the wanton destruction a fox can perpetrate in a chicken coop, will attest to this. We are in truth part of nature, so why do we believe our creations are somehow not? In this book I will try to explore this phenomenon, where it comes from and what problems it has created. I will also try to analyse how a change in these perceptions can help in making our activities generally more sustainable. In this I will make 
particular reference to the car. The car has, after the agricultural revolution and the industrial revolution, probably of all human interventions, had the greatest impact in terms of shaping our environment and is therefore worthy of special analysis. It is by far the most complex of consumer goods and I happen to spend a lot of my time studying the car and the industry it created. Like many people, I just happen to like cars, even though I rarely use them for commuting as cycling and walking suit me better than sitting in a traffic jam.

As outlined earlier, this may be one of the more unusual books on cars you will read. I do hope you bear with me. If you do, I may be able to convince you that there is more to cars and our relationship with them than most people think. You may also find that in order to make automobility even approach sustainability, we need a radical rethink, not only about the car itself, but our whole society, its culture and its relationship with the natural environment. The car is very much a symbol, both of our achievements as humans, but also of our alienation from the rest of creation. Bringing these two elements of human activity into closer harmony is essential if we want to continue to be able to hit the road.

\subsection{OUR ALIENATION FROM NATURE}

In her 2011 book, On Extinction, Melanie Challenger explored the process by which we came to see ourselves and, by implication, our creations as separate from nature. She traces it to the invention of agriculture. This is an interesting angle. Although often presented as a clever innovation that had mainly positive impacts, others have shown that not only were early agriculturalists less healthy than their hunter-gatherer ancestors, enjoying shorter lifespans (Rudgley, 1998), but that the origins of our impacts on the climate also lie with this earlier revolution, not just with the later, industrial revolution (Ruddiman, 2005). Ruddiman shows that the start of agriculture also brought about a start in the increase in carbon dioxide $\left(\mathrm{CO}_{2}\right)$ and methane emissions that depart from expected trends. $\mathrm{He}$ attributes this to deforestation to clear land for cultivation, the start of cattle rearing and the beginning of wet rice cultivation by humans - a significant source of methane.

Challenger (2011) argues that another one of the less than positive impacts of the agricultural revolution was that it gave us the impression of greater control over nature than we had previously thought possible. She explains, for example, that while Socrates argued that all creatures benefit equally from nature's gifts, it was also clear that humans benefit more than any other species from what those species themselves provide, deriving 
considerable benefit from sheep, goats, horses and cattle. Diamond (1998) added to this notion in his explanation for why humans in some parts of the world achieved greater technological and agricultural complexity centres on the availability of cultivatable crops and practical animals capable of domestication in those parts of the world. Cicero continued Socrates' argument, as Challenger (2011: 47) explains, by emphasizing the fact that animals have no knowledge of agriculture, which automatically separates them from us. We now know that animals are also capable of managing their environments for their own benefits as outlined briefly above, practising activities comparable to agriculture, thereby undermining this notion somewhat. Even the humble ant - arguably the most successful species on our planet - farms aphids for the sugary substance they produce.

Most of the great religions grew out of agricultural societies, ${ }^{1}$ and many of them therefore adopted this distinction between us and them, going as far in some cases as to argue that the rest of creation was clearly there primarily for our benefit. This is a strong streak in Christianity for example, the West's dominant belief system. Challenger quotes St Thomas Aquinas, who maintains 'that other creatures are ruled by God by means of intellectual creatures'; the latter presumably includes us. Others, notably Attfield (1991), have argued that there is in fact a clear environmental strand within Christianity. However, this tends to be cast more within the context of 'stewardship'. It therefore perpetuates the notion that we are separate from the rest of creation, albeit casting us as benevolent protectors of that rest of creation rather than merely exploiters of creation - it casts us in the still popular role of 'conservationists'. Yet this notion of separateness but in a benevolent manner is also proving unhelpful in the context of environmental sustainability, as it again separates us from our own impacts - we are left protecting 'the planet', or 'the environment', from us, with both somehow separate from us. This also gives us the option of doing environmental protection at a time that suits us and in places that suit us, the notion of conservation, national parks, etc. In reality our planet can very much look after itself - although through processes that do not necessarily include us in the equation. Instead, what we are really protecting or conserving is our environment: ecosystems from which we derive benefit, our ability to live and thrive on our planet. Environmental legislation, for this reason, is usually more about protecting human health than about protecting 'the planet', and this bias is perfectly understandable.

The environmental movement, particularly in North America, has long looked to tribal societies as well placed to provide answers to some of these issues. In particular, the idea that such societies are somehow 'closer' to nature, or more integrated with nature, proves fertile ground 
for environmentalism. Such tribal societies often adhere to older, preagricultural belief systems. Pre-agricultural belief systems, which in many cases persisted into agricultural societies, such as the Hopi, emphasized various types of nature worship, an approach that could be generalized as 'shamanistic' or 'animist'. The role of the shaman is to communicate between our world and various 'other' worlds dominated by spirits, many of them linked with other species, often animals (e.g. Harner, [1980] 1990). Animals are often seen as ancestors, or at least relatives, and may be cast as culture heroes, such as raven in the cultures of the Pacific north-west, Alaska and the First Nations of British Columbia. Shamanism or related belief systems have persisted in, for example, Shintoism in Japan, shamanism in Korea and Taoism in China, although in all of these locations it was subsequently joined by Buddhism and/or Confucianism, which ultimately became the dominant belief systems in these countries. More recently, Marxist systems have also played a role in East Asia, albeit with many local characteristics. In this context it is worth noting that Friedrich Engels once warned: 'Let us not ... flatter ourselves on account of our human victories over nature. For each such victory takes its revenge on us ...' (Engels, 1974).

While the notion of the 'noble savage', with its origins in the 18thcentury Enlightenment, may be overplayed by some modern environmentalists, it is certainly true that many non-Western societies understand our relationship with the rest of creation differently. I will touch on some of this below, particularly in the context of how different societies relate to human creations, including cars, differently from us. Clearly, if you see humans as fully integrated with the rest of the natural environment, conceiving of human creations as anything other than natural is not an option - it is not allowed for in your world view. The analysis presented by Lipton and Bhaerman (2011) is probably helpful in this respect in that they argue that human development has long involved attempts to balance the material and the non-material, or spiritual, realm. Over time, human civilizations have rarely been able to achieve a perfect balance between the two, on the whole favouring one or the other.

The authors argue that starting with animism, which they trace back to the period before $8000 \mathrm{BC}$ (they take a largely Eurocentric perspective here), we have a period when this balance was achieved. This still covers most of human existence. They define the next phase of moving into the spiritual realm as polytheism, which they position up to around $2000 \mathrm{BC}$, then moving further into the spiritual realm towards monotheism focused around AD 800 . They then identify a gradual move back within the spiritual realm towards the centre and the boundary with materialism with the reformation at around AD 1500, then to deism around AD 1776. With 
deism, they argue, the balance between the material and spiritual is once again restored, albeit briefly. This Age of Enlightenment brings a new understanding of the material world, while still engaging with the spiritual. The next phase of scientific materialism takes us well into the material realm, where they identify Darwinism (1859) as the focal point. This period saw, for example, the invention of the car, and it reached its extreme with the discovery of DNA by Crick and Watson in 1953, a phase they term neo-Darwinism, when the extreme of the human journey into the material realm was reached; we had now discovered the ultimate secret of life and it was chemical. However, in this analysis we then see a turning of the tide with a move back towards the spiritual as doubts have crept in about our understanding of nature and our ability to manipulate it. Many such doubts stem from our increasing inability to square our dominant explanatory system with what we find in the realm of quantum physics (Capra, 1975). Lipton and Bhaerman (2011: 63) identify the Human Genome Project (2001) as a key event in this current trend towards restoring the material-spiritual equilibrium. They list, for example, the resurgence in fundamentalist religion as a clear sign of this.

However, their own take on all this is that neither religion nor science has in reality been able to disconnect us from nature and that a new story is now needed that recognizes this simple fact. If we can somehow return to regarding ourselves as the integral part of nature that we are, this could have a number of implications, most of them positive. In fact many of our actions may already indicate that our notion of separateness from nature is in truth quite wrong. When I grew up, seeing a bird of prey was a rare event, while the Rhine was too polluted for salmon. Now both have been turned around - I frequently see birds of prey, and salmon are once again able to swim up the river Rhine. Why? Simply because we recognized the problem and did something about it - we adjusted our behaviour and dedicated resources to rectifying the damage we had done. Despite this, extinctions are at a record level, but we are at least aware of this. Is it possible that our ability to recognize such environmental degradation and act to rectify it is also itself part of a natural process of maintaining, or re-establishing, equilibrium? In other words, is our environmental concern the product of a natural process whereby we are given the natural ability to recognize a lack of equilibrium while also giving us the natural ability to prioritize the restoration of such an equilibrium - if we choose to - and using our creativity to work towards achieving this? Could all this, in other words, also be part of the way in which nature operates? In their important, though largely ignored, piece Field and Conn (2007) explain that what does distinguish us from the rest of creation - as far as we are aware - is the fact that we have foresight and insight. Given these natural laws, to which we are subject, 
we can determine possible solutions to these problems and act upon them. These abilities in themselves are part of our 'nature' and could therefore be, or perhaps are even likely to be, part of the processes in which nature itself operates. These abilities can be '. . . used to precipitate death as well as to sustain life ...', however (Field and Conn, 2007: 343). It may just be possible that once having 'precipitated death', we eventually see sense as part of nature's mechanism to maintain equilibrium, and therefore change tack and proceed to 'sustain life' and sort things out.

Walker and Salt (2006) explain that natural systems can achieve equilibrium in various different states of varying stability. Some of these are more suited to us than others and are therefore more desirable for us; they ensure or facilitate our survival or comfort. However, the system, or indeed the planet, can exist in any of these states; any of these can be stable in its own way. So, therefore, we very often seek to stabilize a particular natural state because it brings those ecosystem benefits we are after. Even when we protect nature, we are therefore shaping it. They give examples from the Florida Everglades, the Goulburn-Broken catchment in Australia and other ecosystems to illustrate this notion. Even 'natural' landscapes, as we see them, are shaped by climate change and by human input; the 'pristine' Scottish Highlands are a case in point, shaped as their landscape is by climate change, agricultural and forestry practices, the removal and introduction of species, etc. Similarly, Indigenous Australians have long used fire to shape the 'natural' Australian landscape.

In reality, we humans have become totally intertwined with our technology, such that humans and their technology combined constitute our species. Technology is a natural human characteristic in the way black and white fur is a characteristic of the giant panda. We would now struggle to survive without cooking our food, which requires the technology of controlling fire, kill much of our prey, which requires the technology of weapons and traps, or grow our crops, which requires the technologies of tools to work the soil and harvest plants. To a large extent we have co-evolved with our technologies - we make them to suit us and adapt to them such that we increasingly suit them (Spyker, 2007). Our control of fire allowed us to keep predators at bay, change our environment and cook our food (Lipton and Bhaerman, 2011). Similarly, our stone tools do a job for us and then we adapt to become better at making and using them (Reardon, 2013b). What is true for fire and stone tools is true for all our technologies, all our creations ranging from a carefully dressed arrowhead to an iPhone. Technology is part of our nature and technology is thus a natural phenomenon. We shape it and in turn we are shaped by it. This also undermines the notion that the wheel does not occur in nature - it does: we use it on our vehicles. 
On an ethical level, Kohak (1985: 35-36) explored the intrinsic value and our inherent moral obligations towards our artefacts:

Artifacts are not only products but also gifts, be it of God or of Nature. Their being has been bought at a price, be it of animals slaughtered, trees felled, ore mined. A gift, though, requires gratitude as a response. It is surely one of the most elementary prima facie obligations to treat a gift with respect ... It might, to be sure, sound farfetched to speak of my moral obligation to an aluminum beer can discarded by the road side, yet that obligation is real. That aluminum, embodying both a prodigious amount of labor and a part of God's creation - or, in a secular metaphor, a non-renewable natural resource, is a gift. Though it might be my privilege to use that resource, that gift, it is immoral for me to waste it.

It is likely that technology is used by nature as part of our role in natural systems; nature will thus use our technological aptitudes to help it in its efforts to achieve equilibrium in the natural systems of which we are part. If this is indeed how humankind operates, with nature acting through us in a sociological and psychological fashion, then there is mounting evidence even for those who still believe that we are somehow separate from, or even above, the rest of creation - that in fact we are an integral part of nature and part of the natural processes used to maintain equilibrium; that we are in fact part of nature's resilience and resistance. Indeed, Lipton and Bhaerman (2011: 209) also argue that 'humans, like every other organism in the biosphere, are here to support environmental balance, to buffer it, to sustain it, and to encourage harmony'. We are not, as some deep greens like to portray us, a blot on the landscape causing only harm and no good; we are natural. They add, like Field and Conn (2007), that we are unique in our awareness of our evolution and of our potential for change. We can therefore gain awareness of our role in maintaining harmony in natural systems and act accordingly.

As part of this new approach we also need to change our relationship with the objects around us. For example, we need to start looking at objects as systems, rather than single entities, an approach to which cars lend themselves particularly well. Cars are themselves made up of some 15000 components all working - ideally - in perfect harmony to deliver us personal mobility, identity, fun, while they are part of a system of conception, production, distribution and use that all contribute to the very complex system of 'automobility'. In this sense, an ecosystem approach is like systems theory. Meadows (2009) is a useful source here as she combines expertise in systems thinking with expertise in sustainability thinking. Natural and human-made objects become part of the same system in this context, deserving of similar, though not always equal, attention.

It is important here to understand our position in time and space. 
In time, due to evolution, we are essentially a snapshot in a continuing process. 'Humans' are a point along an evolutionary continuum and it is very difficult to pinpoint at what point along that continuum we became human and no longer humanoid, or ape, or whatever we choose to call it. Looking forward it will also be very difficult - except with hindsight - to determine at what point we will have evolved into another 'post-human' species. In terms of place, we need to realize that we are made up of the same atoms as everything else on this planet and, in fact, in the universe, the source of all those atoms. The iron atoms in our blood are the same type of iron atoms as those in the Earth's crust, at the Earth's core and in our car. This emphasizes the point made earlier that, in very physical terms, we are connected with everything around us, animal, vegetable and mineral - including our cars; we are all made of the same stuff.

Lipton and Bhaerman (2011: 18) point out that ' $\ldots$ the primary characteristic of life is movement'. To this extent, then, are cars 'alive'? Just think how easy it is to accept that the cars in the Disney Pixar film Cars are animate; are cars then in some sense a life form? And, does it matter? Interestingly enough, some recent research has confirmed that most of us do not see cars as mere inanimate objects. The brain organizes things in terms of categories, or, as us general linguists would call them, 'semantic categories'. Research carried out at the University of California at Berkeley found that for many people, vehicles and animals fall into the same category (Huth et al., 2012). Reardon (2013a) finds this surprising. I do not; I think this makes perfect sense. Perhaps by the time you have finished this book, you will agree.

\section{NOTE}

1. Although note that recent discoveries in south-eastern Turkey have revealed evidence of organized religion that pre-dates the Neolithic revolution (Ananthaswamy, 2013). 